\title{
Enzymatic production of linear long-chain dextrin from sago (Metroxylon sagu) starch
}

\begin{abstract}
Pullulanase (EC.3.2.1.41) was used to generate more linear-chain dextrin from sago starch (24.9\% amylose) such that the resulting product could act as a high amylose starch. A starch suspension of $5.0 \%(\mathrm{w} / \mathrm{v})$ sago starch was heated at $100{ }^{\circ} \mathrm{C}$ for $45 \mathrm{~min}$ and, after cooling, the gelatinized sago starch was hydrolyzed with $2.0 \%$ (v/dry weight starch) pullulanase (Promozyme 400L, Novozymes A/S, Denmark) for $24 \mathrm{~h}$. The linear long-chain dextrin (LLD) content of the hydrolysate after drying, was then compared with the initial LLD content. The surface morphology of the starch granules was observed with a scanning electron microscope (SEM). The effects of gelatinization, time of reaction, pretreatment with different strengths of hydrochloric acid prior to enzyme hydrolysis, and starch and enzyme concentrations were studied. Raw sago starch was resistant to the action of pullulanase, but caused an increase in the LLD of that sago starch from an initial concentration of 24.9-33.2\% following gelatinization. The best conditions to maximize the amount of LLD were $5.0 \%$ (w/v) sago starch, $2.0 \%$ (v/w) enzyme and $12 \mathrm{~h}$ reaction time. Acid pretreatment of the sago starch did not cause greater improvement in the accessibility and susceptibility of pullulanase as the LLD content, following pullulanase action did not change significantly. Shrinkage on the surface of the starch granules was observed with the SEM.
\end{abstract}

Keyword: Linear long-chain dextrin, Pullulanase, Sago starch, Acid hydrolysis 